\title{
Methotrexate pharmacogenomics
}

\section{J M Kremer}

\section{Observations of clinical effects of methotrexate will help in patient- management decisions}

A n unprecedented confluence of events has led to insight into how methotrexate (MTX) exerts its therapeutic and toxic effects in patients receiving the low weekly doses used in rheumatic diseases. Because of the prevalence of genetic variations (single-nucleotide polymorphisms (SNPs)) in enzymes associated with the metabolism of MTX and regeneration of reduced folate, some SNPs may be associated with clinical variations in patients receiving the drug.

MTX is one of the best-studied drugs, and there exists an unusually rich opportunity to explore and understand a large variety of well-described enzyme pathways, each with a variety of SNPs that may be relevant to the effects of MTX. There has recently been an interest in the association of folate pathway SNPs with the clinical effects of MTX. Observations of the clinical effects of MTX in patients with known enzyme SNPs will help clinicians derive practical insights that can help with patient management decisions. All that is needed then to determine whether certain folate enzyme pathway SNPs were associated with clinical, laboratory or toxic effects is the ability to document what these SNPs were in different populations and closely observe patients who were receiving the drug.

In this issue of Annals of the Rheumatic Diseases, Hughes et al ${ }^{2}$ report on racial differences in certain SNPs of the methylene tetrahydrofolate reductase (MTHFR) enzyme, and its effect on certain side effects of MTX. Of the many enzyme systems associated with SNPs that could affect patients receiving MTX, perhaps MTHFR is the best studied. As can be seen in fig 1 , it is a critical enzyme associated with the regeneration of 5-methyl-tetrahydrofolate from 5,10-methylene-tetrahydrofolate. The regenerated 5-methyl-tetrahydrofolate contributes a methyl group to homocysteine for regeneration of methionine, using $\mathrm{B}_{12}$ as a necessary cofactor. Thus, in the absence of adequate amounts of 5-methyl-tetrahydrofolate, more homocysteine accumulates and less methionine is regenerated. As methionine is a precursor in a myriad of downstream-1 carbon transfers, it is easy to see that a genetic defect in its regeneration can lead to the potential for toxicities associated with both hyperhomocysteinaemia and methionine deficiency. ${ }^{3}$ The relative position of MTHFR in many enzymes associated with the metabolism of MTX and regeneration of reduced folate is shown in fig 2 .

MTHFR deficiency is the most common inherited folate metabolism disorder. ${ }^{5}$ A severe deficiency is associated with neuropathy and encephalopathy as well as vasculopathy and coagulopathy. ${ }^{5}$ The neuropathy and encephalopathy toxicities are also seen with the neurotoxicity associated with $\mathrm{B}_{12}$ deficiency. The wild-type (CC) polymorphism in the C677T genotype is associated with normal activity, whereas the CT heterozygote, found in $40 \%$ of the population, is associated with a $40 \%$ decrease in the ability to regenerate 5-methyl-tetrahydrofolate. The homozygotic TT genotype is found in $8-12 \%$ of the population and is associated with a $70 \%$ decrease in the ability to regenerate 5-methyl-tetrahydrofolate. $^{5}$

When MTX was given intravenously for the treatment of leukaemia, the TT genotype was associated with increased incidence of mucositis and slowed recovery of platelet counts. ${ }^{6}$ Van Ede et $\mathrm{al}^{7}$ studied the C677T and A1298 polymorphisms in a Dutch population of 236 patients with rheumatoid arthritis. In a prospective, double-blind, placebo-controlled study, the authors ${ }^{7}$ described a TT and CT genotype prevalence of $8 \%$ and $40 \%$, respectively, and a CC prevalence of $52 \%$ in this Caucasian population. Both the TT and TC genotypic variants were associated with increased MTX toxicity and discontinuation rates.

The C677T and Al298T polymorphisms were examined in a population of 106 patients with rheumatoid arthritis. ${ }^{8}$ The prevalence of the TT and CT polymorphism was $17 \%$ and $50 \%$ in this population, with the wild-type CC allele observed in only 33\%. The authors also reported that the distribution of the A1298T alleles AA, AC and CC was 70\%, $27 \%$ and $3 \%$, respectively. Patients with the non-wild-type polymorphisms were more likely to have both efficacy and toxicity, with $\mathrm{T}$ at $\mathrm{C} 677 \mathrm{~T}$ and $\mathrm{C}$ at Al298C associated with toxicity (table 1). ${ }^{7-9}$

Dervieux et $a l^{10}$ studied the effects of three different folate pathway enzyme SNPs on the clinical effects of MTX in a cross-sectional study of 108 patients. Patients who were homozygotic for mutant (non-wild-type) alleles of amino imidazole ribonucleotide transformylase (ATIC 347GG), the reduced folate carrier (RFC-1 80AA) and thymidylate

Table 1 MTHFR genotyping: published literature

\begin{tabular}{|c|c|c|c|c|c|}
\hline Author & Objective/study design & n & Polymorphisms & Treatment regimens & Results \\
\hline Ulrich et al & $\begin{array}{l}\text { C677T modification } \\
\text { of response to MTX } \\
\text { Retrospective }\end{array}$ & $\begin{array}{l}220 \\
\text { CML } \\
\text { BMT }\end{array}$ & $\begin{array}{l}\Pi=16 \% \\
C T=42 \% \\
C C=42 \%\end{array}$ & $\begin{array}{l}\text { MTX intravenous } \times 4 \text { doses } \\
\text { Folate/folic acid unknown }\end{array}$ & $\begin{array}{l}\Pi \text { genotype associated with } \uparrow \\
\text { toxicity (mucositis, } \downarrow \text { platelet } \\
\text { recovery) }\end{array}$ \\
\hline Van Ede et al & $\begin{array}{l}\text { Relationship between } \\
\text { C677T and efficacy } \\
\text { and toxicity of } \\
\text { MTX } \\
\text { Prospective, DB, PC }\end{array}$ & $\begin{array}{l}236 \\
\text { RA }\end{array}$ & $\begin{array}{l}\Pi=8 \% \\
C T=40 \% \\
C C=52 \%\end{array}$ & $\begin{array}{l}\text { MTX } \\
\text { MTX and folate } \\
\text { MTX and folic acid }\end{array}$ & $\begin{array}{l}\mathrm{T} / \mathrm{T} \text { and } \mathrm{T} / \mathrm{C} \text { genotypes } \\
\text { associated with } \uparrow \text { toxicity and } \\
\text { MTX discontinuation }\end{array}$ \\
\hline Urano et $a^{\beta}$ & $\begin{array}{l}\text { C677T and A1298T } \\
\text { association with MTX } \\
\text { efficacy and toxicity } \\
\text { Retrospective }\end{array}$ & $\begin{array}{l}106 \\
\text { RA }\end{array}$ & $\begin{array}{l}\Pi T=17 \% \\
C T=50 \% \\
C C=33 \% \\
A C=27 \% \\
C C=3 \%\end{array}$ & $\begin{array}{l}\text { MTX doses variable } \\
\text { (MTX treatment had been } \\
\text { discontinued in some patients) } \\
\text { Folic acid not given in most cases }\end{array}$ & $\begin{array}{l}\text { Prevalence of polymorphisms was } \\
\text { reported to be associated with } \\
\text { both MTX efficacy and toxicity } \\
\text { T at C } 677 T \text { and C at A } 1298 \mathrm{C}- \\
\text { toxicity }\end{array}$ \\
\hline
\end{tabular}

BMT, bone marrow transplant; CML, chronic myelogenous leukaemia; DB, double blind; MTHFR, methylene tetrahydrofolate reductase; MTX, methotrexate; PC, placebo controlled; RA, rheumatoid arthritis. ${ }^{7-9}$ 


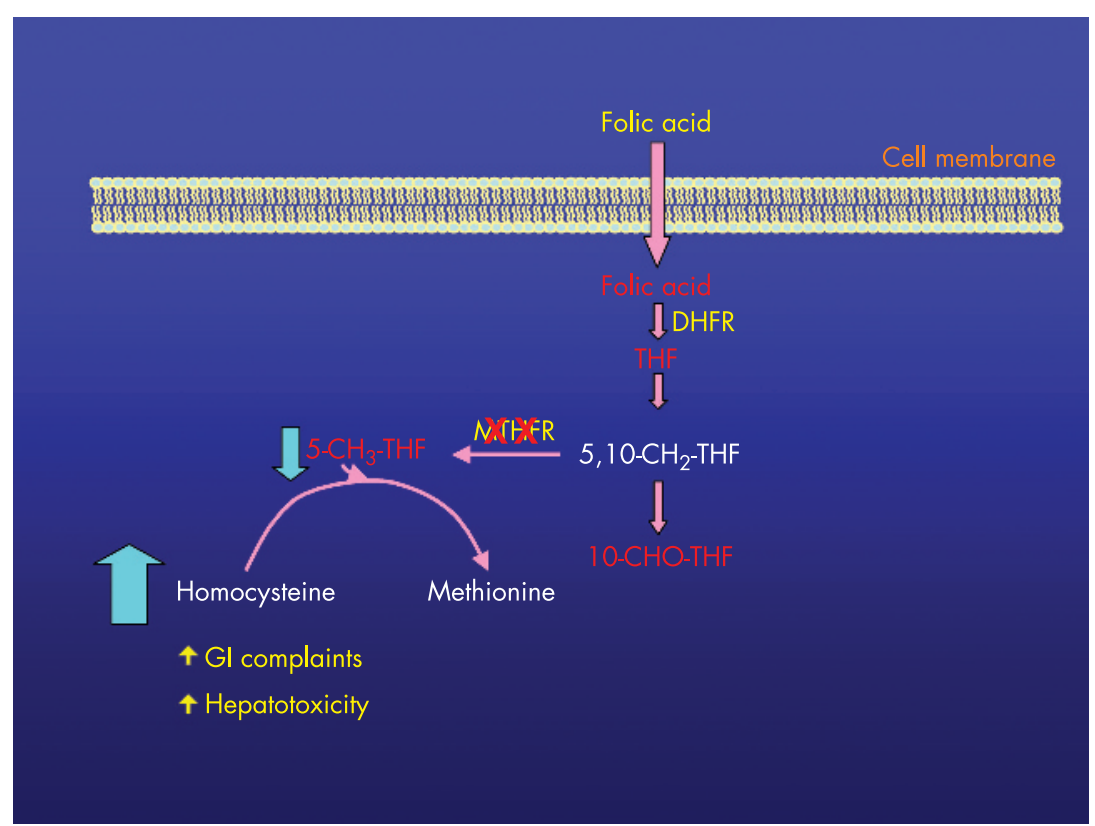

Figure 1 Effect of C677T polymorphisms of the methylene tetrahydrofolate reductase (MTHFR) enzymes and regeneration of methionine from homocysteine. XX over MTHFR represents a gene polymorphism with decreased ability to regenerate 5- $\mathrm{CH}_{3}$ THF. $5-\mathrm{CH}_{3}$ - THF, 5-methyl

tetrahydrofolate; 5,10- $\mathrm{CH}_{2}-\mathrm{THF}, 5,10$-methylene tetrahydrofolate; 10-CHO-THF, 10-formyl tetrahydrofolate; DHFR, dihydrofolate reductase; $\mathrm{Gl}$, gastrointestinal; THF, tetrahydrofolate. Adapted from Schwahn and Rozen. ${ }^{5}$

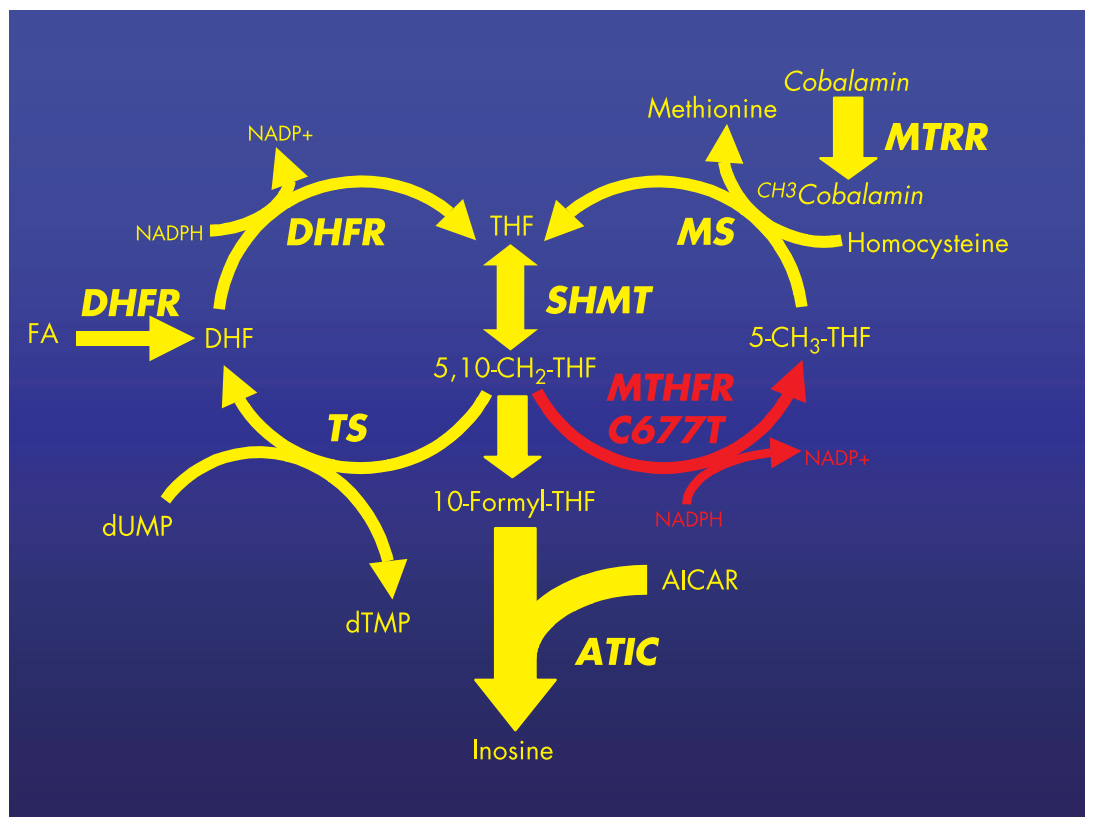

Figure 2 Folate enzymes and intermediate moieties. AICAR, 5-aminoimidazole-4-carboxamide ribonucleotide; ATIC, amino imidazole ribonucleotide transformylase; 5- $\mathrm{CH}_{3}-\mathrm{THF}$, 5-methyl tetrahydrofolate; 5,10- $\mathrm{CH}_{2}$-THF, 5, 10-methyl tetrahydrofolate; DHF, 2,5-dihydrofuran; DHFR, dihydrofolate reductase; dTMP, thymidylate monophosphate; dUMP, deoxyuridine monophosphate; FA, folic acid; MS, methionine synthase; MTHFR, methylene tetrahydrofolate reductase; MTRR, methionine synthase reductase; NADP, nicotinamide-adenine dinucleotide phosphate; $N A D P H$, reduced form of NADP; SHMT, serine hydroxymethyltransferase. 
synthase $\left(\mathrm{TSER}^{\star} 2{ }^{*} 2\right.$; fig 2 ) were more likely to respond better to MTX than patients without any of the homozygotic variant genotypes. The concept of a genetic index was introduced, which summed the presence of any of these SNPs, creating a profile of patients who responded better to the drug.

In a recently published report, many of the same authors looked at a crosssectional study of a different group of enzyme SNPs in 214 patients on MTX enrolled at four study sites. SNPs in four folate enzymes, including MTHFR, thymidylate synthase, amino imidazole ribonucleotide transformylase and serine hydroxymethyltransferase 1420CC, were summed and associated with side effects (fig 2). ${ }^{11}$ Risk genotypes markedly associated with side effects in the central nervous system were MTHFR $677 \mathrm{~T}(\mathrm{OR}=3.3)$ and serine hydroxymethyltransferase $1420 \mathrm{CC} \quad(\mathrm{OR}=2.4)$; amino imidazole ribonucleotide transformylase $347 \mathrm{GG}$ was associated with gastrointestinal side effects $(\mathrm{OR}=3.0)$, whereas thymidylate synthase $(\mathrm{OR}=5.4)$ and serine hydroxymethyltransferase 1420cc $(\mathrm{OR}=3.2) \quad$ were associated with alopecia.

A pharmacogenetic index of 3 (variant alleles present in three of the four SNPs tested) was associated with a roughly sevenfold higher likelihood of having a side effect compared with an index of $0 \quad(p<0.01)$. A recently completed prospective dose-escalation study of patients starting MTX for the treatment of rheumatoid arthritis has also shown an association with folate enzyme SNPs and MTX-induced toxicities. ${ }^{12}$

Apparently, several SNPs in folate pathway enzymes are associated with toxicity to MTX. Association with clinical benefit has been more difficult to demonstrate, although some authors $^{812}$ have observed associations with response as well. Clinical response seems to correlate better with actual red blood cell MTX-polyglutamate levels, although there is a clear contribution of folate pathway SNPs. ${ }^{10}{ }^{11}$ The accumulating evidence begs the question of whether the widespread use of a commercially available genetic index would help clinicians to determine who is at greater risk for MTX-associated toxicity, as well as whether a particular patient would be more or less likely to respond to the drug. The ability to access and use a genetic index containing most of the folate pathway enzyme SNPs described, if it were available, would make the most sense. Clinicians could then counsel patients about their likelihood of experiencing MTX-related toxicities, as well as of having a good response to the drug.

Ann Rheum Dis 2006;65:1121-1123.

doi: 10.1136/ard.2006.051789

Correspondence to: J M Kremer, Center for Rheumatology, Albany Medical College, Albany, NY 12206, USA;

jkremer@joint-docs.com

Accepted 16 March 2006

Competing interests: None declared.

\section{REFERENCES}

1 Kremer JM. Toward a better understanding of methotrexate [review]. Arthritis Rheum 2004;50:1370-82.

2 Hughes LB, Beasley MT, Patel H, Tiwari HK, Morgan SL, Baggott JE, et al. Racial/ethnic differences in allele frequencies of single nucleotide polymorphisms in the methylenetetrahydrofolate reductase gene and their influence on response to methotrexate in rheumatoid arthritis. Ann Rheum Dis 2006.
3 Kim RJ, Becker RC. Association between factor V Leiden, prothrombin G20210A, and methylenetetrahydrofolate reductase $\mathrm{C} 677 \mathrm{~T}$ mutations and events of the arterial circulatory system: a meta-analysis of published studies. Am Heart J 2003;146:948-57

4 Gos M Jr, Szpecht-potocka A. Genetic basis of neural tube defects. II. Genes correlated with folate and methionine metabolism. J Appl Genet 2002;43:511-24.

5 Schwahn B, Rozen R. Polymorphisms in the methylenetetrahydrofolate reductase gene: clinical consequences. Am J Pharmacogenomics 2001:189-201.

6 Ulrich CM, Robien K, Sparks R. Pharmacogenetics and folate metabolism: a promising direction. Pharmacogenomics 2002;12:299-313.

7 Van Ede AE, Laan RF, Blom HJ, Huizinga TW, Haagsma CJ, Giesendorf BA, et al. The C677T mutation in the methylenetetrahydrofolate reductase gene: a genetic risk factor for methotrexate related elevation of liver enzymes in rheumatoid arthritis patients. Arthritis Rheum 2001;44:2525-30

8 Urano W, Taniguchi A, Yamanaka H, Tanaka E, Nakajima H, Matsuda Y, et al. Polymorphisms in the methylenetetrahydrofolate reductase gene were associated with both the efficacy and the toxicity of methotrexate used for the treatment of rheumatoid arthritis, as evidenced by single locus and haplotype analyses. Pharmacogenetics 2002; 12:183-90

9 Ulrich CM, Yasui Y, Storb R, Schubert MM Wagner JL, Bigler J, et al. Pharmocogenetics of methotrexate: toxicity among marrow transplantation patients varies with the methylenetetrahydrofolate reductase C677T polymorphism. Blood 2001;98:231-4.

10 Dervieux T, Furst D, Orentas Lein D, Capps R, Smith K, Walsh M, et al. Polyglutamation of methotrexate with common polymorphisms in reduced folate carrier aminoimidazole carboxamide ribonucleotide transformylase, and thymidylate synthase are associated with methotrexate effects in rheumatoid arthritis. Arthritis Rheum 2004:50:2766-74.

11 Weisman MH, Furst DE, Park GS, Kremer JM, Smith KM, Wallace DJ, et al. Risk genotypes in folate-dependent enzymes and their association with methotrexate-related side effects in rheumatoid arthritis. Arthritis Rheum 2006;54:607-12.

12 Kremer J, Orentas LD, Meyer G, Barnham R, Simpson L, Do J, et al. Measurement of erythrocyte methotrexate polyglutamates predicts response to methotrexate therapy in a dose escalation study with rheumatoid arthritis patients [abstract]. Arthritis Rheum 2004;50:S181. 